\title{
Mixed-surfactant aggregation, adsorption, and associated steel corrosion inhibition in salt solution
}

\author{
Y. Zhu* and M. L. Free \\ Metallurgical Engineering, University of Utah, 135 S 1460 E, Rm 412, Salt Lake City, UT, \\ 84112,USA.E-mail: yakun.zhu@utah.edu
}

\begin{abstract}
The corrosion inhibition efficiency of mixtures of three homologous benzalkonium chlorides (BAC) surfactants was investigated using electrochemical measurements and modeling. The surface aggregation concentration (sac) and critical micelle concentration (cmc) of surfactant are useful to evaluate inhibition efficiency. A new cmc prediction model for ternary mixed homologous surfactants of interest has been developed. The model is applicable over a wide concentration range of dissolved salt in solution. The combination of the modified Langmuir adsorption model and the cmc prediction model provides a potential method for inhibition efficiency prediction of various mixed homologous surfactant systems at various dissolved salt concentrations.
\end{abstract}

Keywords: inhibition efficiency; surfactant mixtures; sac; cmc; model and prediction.

Received: September 4, 2015. Published: October 5, 2015

doi: $\underline{10.17675 / 2305-6894-2015-4-4-2}$

\section{Introduction}

The oil and gas industry, as an important component of the national economy, has received considerable attention from researchers. Unfortunately, oil, mining, and transportation equipment have become increasingly difficult to operate because of equipment damage caused by corrosive media, such as $\mathrm{CO}_{2}, \mathrm{Cl}^{-}$, and $\mathrm{H}_{2} \mathrm{~S}[1,2]$. The annual direct cost of corrosion in the US has been estimated to be approximately $\$ 276$ billion or $3.1 \%$ of the gross domestic product (GDP) while corrosion costs between $1.5 \%$ and $5.2 \%$ of the GDPs in other countries [3]. About 3.7\% out of the total cost comes from the oil and gas infrastructure $[1,3]$, which is mainly caused by the corrosion of carbon steel, which is widely used for pipelines $[1,2]$.

Carbon steel is easily corroded in environments that contain water and carbon dioxide $\left(\mathrm{CO}_{2}\right)$ [4]. Dissolved $\mathrm{CO}_{2}$ in water and crude oil can cause tremendous damage to pipelines and structural components [1,5-7]. These problems have led to great interest in industry and academia to control $\mathrm{CO}_{2}$-related corrosion. The most popular control method is to use organic inhibitors, many of which are surfactants with hydrophilic and hydrophobic molecular sections [8-10]. Upon addition to a pipe (steel)-water-oil environment, surfactants can be involved in adsorption, partitioning, and aggregation [11].

The hydrophilic group of surfactant strongly prefers interaction with polar entities such as water, metals, and other ions. Generally these organic compounds adsorb on the 
steel surface, block the active sites exposed to corrosive media, and thereby reduce corrosion attack $[12,13]$. It is believed that the molecular structure of these heterocyclic compounds plays a dominant role in the corrosion inhibition performance. The presence and structure of specific atoms, such as $\mathrm{C}, \mathrm{H}, \mathrm{N}$ and $\mathrm{O}$, in these compounds determines the adsorption mechanism and corrosion inhibition efficiency [14, 15].

In practical applications surfactant mixtures have received wide attention due to their superior physicochemical properties and capabilities in efficient solubilization, dispersion, suspension, and transportation [16,17]. Solutions of mixed surfactants can often be conveniently tuned to achieve desired properties by adjusting the mixture composition. More surface-active and expensive surfactants are often mixed with less surface-active and less expensive surfactants to reduce cost [18]. Natural mixtures of surfactants are also commonly used to avoid costly separations. However, the authors are not aware of a completely established theory or model to adequately predict the corrosion inhibition on carbon steel of various mixed surfactants despite extensive research work.

The hydrophobic portion strongly prefers interaction with hydrophobic entities such as hydrocarbon phases. When an aqueous surfactant solution comes into contact with an immiscible organic liquid, surfactant monomers may prefer partitioning into organic liquid until equilibrium is reached between the two liquids. Partitioning is usually characterized by the partitioning coefficient, which is defined as the ratio of monomeric surfactant concentration in oil to that in water [19]. For mixed surfactants, the phenomenon becomes more complicated in terms of equilibrium mixture composition in each phase, the effect of individual mixed species on the partitioning, and the adsorption of mixture at the oil/water interface. It has been shown that for some non-ionic pure surfactants, a plateau aqueous concentration of monomer beyond the critical micelle concentration $(\mathrm{cmc})$ is reached with increasing total surfactant concentration [20]. However, the total amount of surfactant partitioned into oil phase continues to increase beyond the mixed cmc [20-22], which makes the experimental investigation and quantitative modeling of mixed surfactant partitioning more complicated.

In other words, surfactant molecules tend to adsorb at the air-liquid interface, liquidsolid interface, or liquid-liquid interface to escape from water by associating and aggregating hydrocarbon chains together. The concentration at which a monomer layer of surfactant forms at the interface is considered as surface aggregation concentration (sac). If there are no spaces available for adsorption, they will form aggregate structures to orient their hydrophobic tails toward those of neighboring surfactant molecules and their hydrophilic head groups toward water. The concentration at which the surfactants start to form aggregation in solution as micelles is termed the cmc. One of the challenges in the study of aggregation properties, such as cmc, comes from the effects of specific ions and added salts on the aggregation properties of surfactants. It is accepted that the major effects of specific ions arises from counterion interactions with surfactant headgroups at relatively low to intermediate salt concentration. The effect of coion can become increasingly dominant as the added salt (containing coion) concentration increases [23-25]. To the best 
knowledge of the authors a comprehensive theory or model to adequately describe the effects of ion specificity and binding mechanism on surfactant aggregation properties has not been developed yet.

In the present study, the corrosion inhibition efficiency (IE) of different mixtures of three homologous cationic surfactants of benzalkonium chlorides, $\mathrm{C} 12 \mathrm{Cl}$ (or $\mathrm{C} 12$ ), $\mathrm{C} 14 \mathrm{Cl}$ (or $\mathrm{C} 14$ ), and $\mathrm{C} 16 \mathrm{Cl}$ (or $\mathrm{C} 16$ ), were investigated using electrochemical measurements. The $\mathrm{sac}$, instead of $\mathrm{cmc}$, is shown as a characteristic of monolayer formation at the electrodesolution interface. A new cmc and corrosion inhibition efficiency prediction model for ternary mixtures of homologous surfactants was developed. For $\mathrm{cmc}$ prediction, the model is simple, easy to apply, and has few assumptions. The inputs are a few cmc values of pure surfactants in solution without electrolyte and its outputs include cmc values of ternary mixed BAC at various mixed ratios over a wide range of background electrolyte concentration (up to $0.856 \mathrm{M} \mathrm{NaCl}$ ). Based on the electrochemical measurement results and by incorporation of the Langmuir adsorption model, the corrosion inhibition efficiency over wide ranging conditions of relevant mixtures is accurately predicted.

\section{Experimental procedures and materials}

The surfactants used in this study are homologous cationic surfactants benzalkonium chlorides (BAC), including benzyl dimethyl dodecyl ammonium chloride $(\mathrm{C} 12 \mathrm{Cl})$, benzyl dimethyl tetradecyl ammonium chloride $(\mathrm{C} 14 \mathrm{Cl})$, and benzyl dimethyl hexadecyl ammonium chloride $(\mathrm{C} 16 \mathrm{Cl})$ with assay values higher than $99 \%$.

The test samples for surface tension measurements were prepared by sequential dilution of concentrated aqueous solutions of surfactants using double deionized water. The stock solution was prepared at a total surfactant concentration of $25 \mathrm{mM}$ for electrochemical measurements using deionized water.

A piece of X65 steel was used as the working electrode in electrochemical measurements with a surface area of $0.196 \mathrm{~cm}^{2}$. The composition (wt \%) is $\mathrm{C} 0.06 \%, \mathrm{Mn}$ $1.33 \%$, P $0.007 \%$, S $0.005 \%$, Si $0.30 \%$, Cu $0.30 \%$, Ni $0.10 \%$, V $0.022 \%$, Cb $0.046 \%$, Al $0.019 \%$, Cr $0.05 \%$, Mo $0.03 \%$, Ti $0.017 \%$, Ca $0.0033 \%$, and Fe (balance).

The surface of the X65 electrode was polished using SiC paper in the sequence of 400-600-800-1200 grit, followed by polishing using polishing cloth with a particle size of $\sim 5 \mu \mathrm{m}$ supplied by Buehler. A platinum ring electrode and a single junction saturated calomel electrode (SCE) were employed as counter and reference electrodes, respectively. Test solutions contained 0.171 or $0.599 \mathrm{M} \mathrm{NaCl}$ and were purged with $\mathrm{Ar}(>99.999 \%)$ for 2 hours (hrs) to remove oxygen followed by a purge of $\mathrm{CO}_{2}(>99.999 \%)$ for $2 \mathrm{hrs}$ to ensure $\mathrm{CO}_{2}$ saturation prior to measurements. A flow of $\mathrm{CO}_{2}$ was maintained during the experiments to keep a positive pressure inside the cell to avoid air ingress. The $\mathrm{pH}$ was adjusted to 4-5 for different mixtures by the addition of $1.0 \mathrm{M} \mathrm{NaHCO}_{3}$ or diluted $\mathrm{HCl}$. The surfactants were added at the beginning of each measurement. The test solutions were then kept at open circuit potential, $E_{\text {corr }}$, for 2 hours for equilibration. Test conditions for different mixed surfactant systems are listed in Table 1. Testing System I is used as the 
primary example for the results discussion and inhibition efficiency prediction model derivation.

Table 1. Experimental condition for different testing systems.

\begin{tabular}{ccccccc}
\hline $\begin{array}{c}\text { Testing } \\
\text { system }\end{array}$ & $\begin{array}{c}\text { Mixed molar ratio } \boldsymbol{a}_{\mathbf{i}} \\
(\mathbf{C 1 2 C l} / \mathbf{C 1 4 C l} / \mathbf{C 1 6 C l})\end{array}$ & Salt $(\mathbf{M})$ & $\begin{array}{c}\text { Measured cmc } \\
(\boldsymbol{\mu M})\end{array}$ & $\boldsymbol{T}\left({ }^{\circ} \mathbf{C}\right)$ & $\mathbf{p H}$ & $\begin{array}{c}\text { Rotation speed } \\
(\mathbf{R P M})\end{array}$ \\
\hline I & $0.70 / 0.25 / 0.05$ & 0.171 & 144 & 40 & 4 & 300 \\
II & $0.33 / 0.33 / 0.33$ & 0.599 & 16.5 & 40 & 5 & 100 \\
\hline
\end{tabular}

Polarization resistance $R_{\mathrm{p}}$ was measured using the linear polarization resistance (LPR) method by polarizing the working electrode $+/-0.010 \mathrm{~V}$ (SCE) $v s . E_{\text {corr }}$ with a sweep rate of $0.1 \mathrm{mV} / \mathrm{s}$. The slope of the tangent at the origin provided the value of $R_{\mathrm{p}}$. Potentiodynamic scans were performed with a sweep rate of $1 \mathrm{mV} / \mathrm{s}$ from $-0.9 \mathrm{~V}$ (SCE) to $-0.35 \mathrm{~V}$ (SCE). Electrochemical impedance spectroscopy (EIS) measurements were made with an applied alternating current $(\mathrm{AC})$ potential of $+/-0.010 \mathrm{~V}$ rms $v s . E_{\text {corr }}$ in the frequency range of 100,000-0.010 Hz. The direct current (DC) potential was set as zero relative to $E_{\text {corr }}$. Each test was repeated at least three times as an independent measurement.

The surface tension of test solutions was measured within a precision of $0.1 \mathrm{mN} / \mathrm{m}$ by the platinum ring setup, equipped with an isothermal vessel holder. All the measurements were performed at a constant temperature of $40 \pm 0.2^{\circ} \mathrm{C}$, which has been shown to be higher than the Krafft point of the surfactants and their mixtures in aqueous media containing various concentrations of $\mathrm{NaCl}$. The constant temperature was maintained through a water circulation bath. The platinum ring was rinsed with water and heated to an orange color using a Bunsen burner between tests to ensure the complete removal of contaminants. Triplicate measurements were used to confirm reproducibility. All values of reported surface tension were determined through the aforementioned procedures.

\section{Results and discussion}

\section{Open circuit potential}

The stability of open circuit potential, $E_{\text {corr }}$, is important to electrochemical measurements. Examples of the dependence of $E_{\text {corr }}$ of X65 steel electrode on time in $0.171 \mathrm{M} \mathrm{NaCl}$ containing aqueous media at $40^{\circ} \mathrm{C}$ are given in Figure 1 . The $E_{\text {corr }}$ stabilized at around $-0.725 \mathrm{~V}$ (SCE) without surfactant. Upon the addition of surfactant to the system of brinecontaining media saturated with $\mathrm{CO}_{2}$, a positive shift of $E_{\text {corr }}$ is usually observed [26]. In the present research $E_{\text {corr }}$ is stabilized between $-0.640 \mathrm{~V}$ (SCE) and $-0.670 \mathrm{~V}$ (SCE) after the introduction of surfactants over a wide concentration range, which includes the sac and the cmc which is around $144 \mu \mathrm{M}$ based on surface tension measurement as shown in Figure 2. $E_{\text {corr }}$ does not increase much at surfactant concentrations above the cmc. The difference in $E_{\text {corr }}$ in the absence and presence of surfactant indicates that the steel surface 
was covered and protected by the inhibitor adsorption. According to Riggs Jr. [27], it is feasible to classify one inhibitor as anodic type or cathodic type if the presence of inhibitor shifts $E_{\text {corr }}$ at least $+85 \mathrm{mV}$ or $-85 \mathrm{mV}$, respectively, relative to $E_{\text {corr }}$ in the absence of inhibitor. However, the positive shift of $E_{\text {corr }}$ of the investigated System I at the highest concentration of $360 \mu \mathrm{M}$ is only around $85 \mathrm{mV}$ suggesting that both the dissolution of iron at the anode and the hydrogen evolution at the cathode were affected.

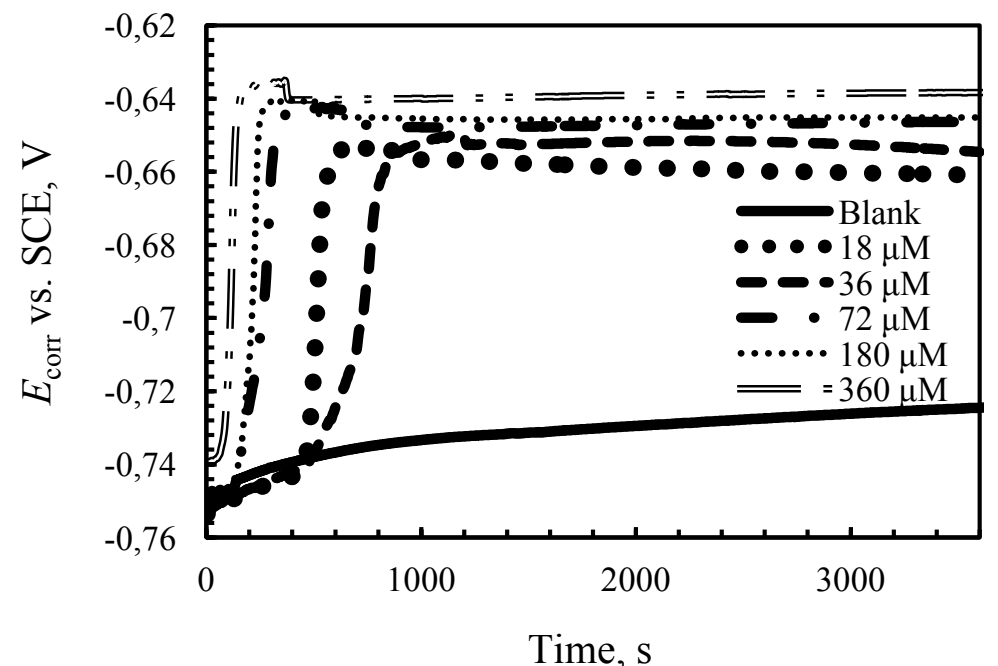

Figure 1. Variation of open circuit potential $E_{\text {corr }}$ with time of X65 electrode immersed in $\mathrm{CO}_{2}$-saturated $0.171 \mathrm{M} \mathrm{NaCl}$-containing media with $\mathrm{pH}=4$ in the absence of surfactant and presence of mixed $\mathrm{C} 12 \mathrm{Cl} / \mathrm{CC} 14 \mathrm{Cl} / \mathrm{C} 16 \mathrm{Cl}=0.70 / 0.25 / 0.05$ at different concentrations.

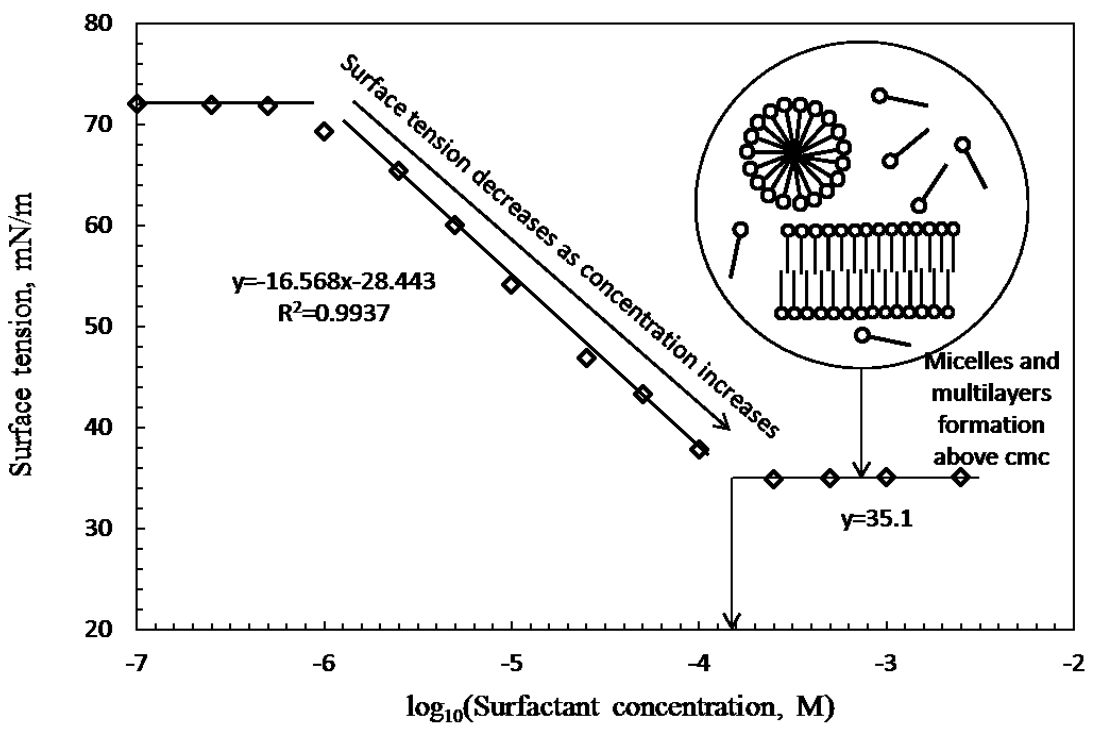

Figure 2. Plots of surface tension versus concentration of mixed surfactants $\mathrm{C} 12 \mathrm{Cl}, \mathrm{C} 14 \mathrm{Cl}, \&$ $\mathrm{C} 16 \mathrm{Cl}$ at ratio of $0.70 / 0.25 / 0.05$ in $0.171 \mathrm{M} \mathrm{NaCl}$-containing aqueous media at $40^{\circ} \mathrm{C}$. The $\mathrm{cmc}$ value is indicated by the arrow. 


\section{Potentiodynamic scan and linear polarization resistance measurement (LPR)}

As the concentration of surfactants inhibitor increases, more and more active surface sites are covered by surfactant molecules and protected against corrosion. Potentiodynamic scans were performed on Testing System I with various concentrations of surfactants. The associated polarization curves are presented in Figure 3. Tafel slopes were estimated from these curves to calculate corrosion current density using the Tafel slope method [28]. The corrosion inhibition efficiency, IE (\%), was calculated using Equation (1) [28].

$$
I E(\%)=100 \times \frac{i_{\text {corr }, 0}-i_{\text {corr }}}{i_{\text {corr }, 0}},
$$

where $i_{\text {corr, } 0}$ and $i_{\text {corr }}$ are the corrosion current density without and with corrosion inhibitors/ surfactants in solution respectively.

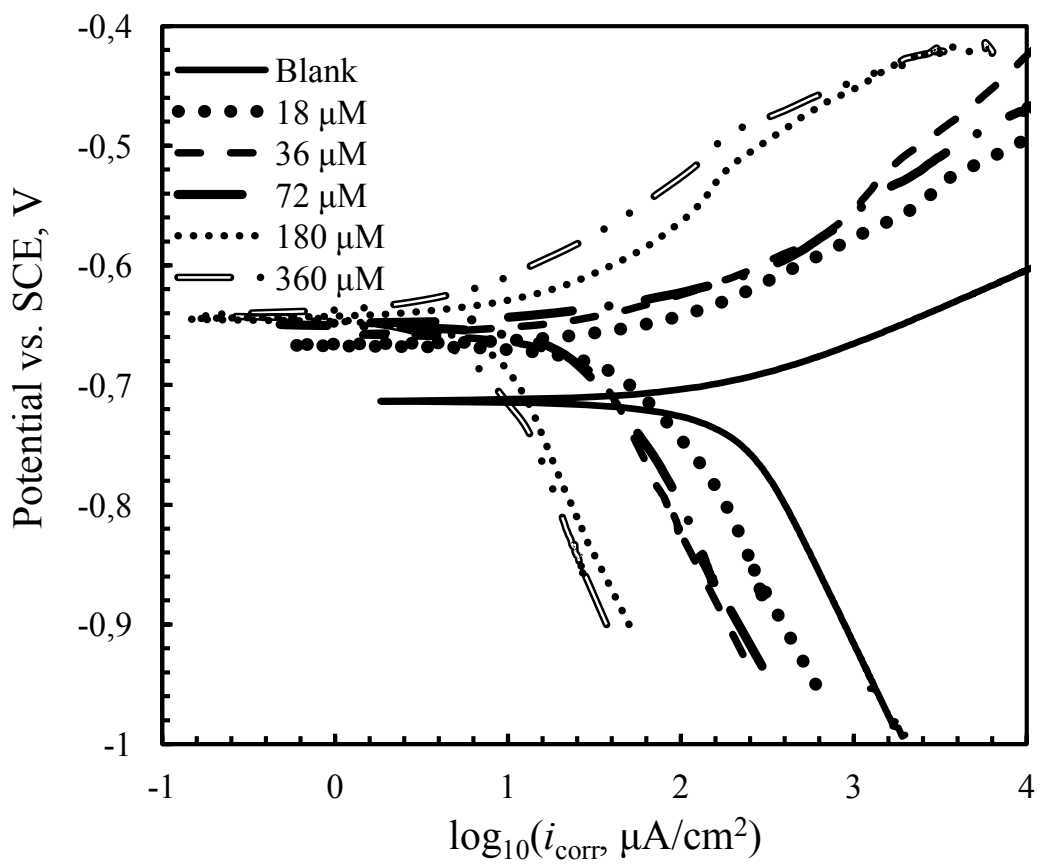

Figure 3. Potentiodynamic polarization curves of $\mathrm{X} 65$ steel exposed in $\mathrm{CO}_{2}$-saturated $0.171 \mathrm{M}$ $\mathrm{NaCl}$ aqueous solution containing various concentrations of mixed surfactants $\mathrm{C} 12 \mathrm{Cl}, \mathrm{C} 14 \mathrm{Cl}, \&$ $\mathrm{C} 16 \mathrm{Cl}$ at ratio of $0.70 / 0.25 / 0.05$ at $40^{\circ} \mathrm{C}$.

The polarization resistance was measured from LPR measurements and was then used to evaluate corrosion inhibition efficiency using Equation (2) with the Tafel slopes estimated from the curve of potentiodynamic scans.

$$
I E(\%)=100 \times \frac{R_{\mathrm{p}}-R_{\mathrm{p}, 0}}{R_{\mathrm{p}}},
$$

where $R_{\mathrm{p}, 0}$ and $R_{\mathrm{p}}$ are polarization resistance in the absence and presence of corrosion inhibitors/surfactants, respectively. 
The results of Tafel slopes polarization resistance, corrosion rate, polarization resistance, and inhibition efficiency are summarized in Table 2 for the Testing System I surfactant mixture. The corrosion inhibition efficiency results from potentiodynamic scans and LPR are very close. As can be seen, inhibition efficiency increases rapidly to around $90 \%$ with the increase in surfactant concentration up to $72 \mu \mathrm{M}$. Further increase in concentration does not effectively enhance inhibition efficiency even when the concentration is much higher than the $\mathrm{cmc}, C_{\mathrm{cmc}}$. The concentration of $72 \mu \mathrm{M}$ is interpreted as the value of sac, $C_{\mathrm{sac}}$, at which a complete monolayer usually forms at the electrodesolution interface, and above which, bilayers/multilayers or semi-spherical/cylindrical micelles usually form at the electrode-solution interface [29,30]. As mentioned in the introduction section, corrosion inhibition is usually directly related to the electrode surface coverage. Therefore, the monolayer is much more effective with respect to corrosion protection and the formation of bilayers/multilayers or micelles do not contribute much to corrosion inhibition.

Table 2. Tafel slopes, corrosion rate, polarization resistance, and $I E(\%)$ for X65 in the absence and presence of Testing System I with different surfactant concentrations.

\begin{tabular}{ccccccc}
\hline $\begin{array}{c}\text { Total } \\
\text { concentration } \\
(\boldsymbol{\mu M})\end{array}$ & $\boldsymbol{\beta}_{\mathbf{a}}\left(\mathbf{m V} \mathbf{d e c}^{-\mathbf{1}}\right)$ & $\boldsymbol{\beta}_{\mathbf{c}}\left(\mathbf{m V} \mathbf{d e c}^{-\mathbf{1}}\right)$ & $\boldsymbol{i}_{\text {corr }}\left(\boldsymbol{\mu} \mathbf{A ~ c m} \mathbf{c m}^{-}\right)$ & $\boldsymbol{I E}(\mathbf{\%})^{\mathbf{a}}$ & $\begin{array}{c}\boldsymbol{R}_{\mathbf{p}} \\
\left(\mathbf{o h m} \cdot \mathbf{c m}^{\mathbf{2}}\right)\end{array}$ & $\boldsymbol{I E}(\mathbf{\%})^{\mathbf{b}}$ \\
\hline 0 & 61.5 & 255 & 202 & 0 & 104 & 0 \\
9 & 65.7 & 248 & 118 & 42 & 188 & 44 \\
18 & 67.1 & 243 & 89 & 56 & 249 & 58 \\
36 & 68.3 & 235 & 53 & 74 & 436 & 76 \\
54 & 63.2 & 245 & 34 & 83 & 643 & 83 \\
72 & 64.8 & 239 & 26 & 87 & 845 & 88 \\
100 & 61.7 & 238 & 13 & 94 & 1591 & 93 \\
140 & 67.9 & 237 & 9 & 96 & 2550 & 96 \\
180 & $61.6^{\mathbf{c}}$ & 245 & 7 & 97 & 2958 & 96 \\
360 & $63.2^{\text {d }}$ & 233 & 5 & 98 & 4282 & 98 \\
\hline
\end{tabular}

${ }^{\mathrm{a}} I E$ (\%) calculated from potentiodynamic scans; ${ }^{\mathrm{b}} I E$ (\%) calculated from LPR; ${ }^{\text {c\&d }}$ derived from the cathodic branch and $\beta_{\mathrm{c}}$ due to lack of sensible linearity in the anodic branch in potentiodynamic scans as seen in Figure 4 [28].

\section{Traditional modeling background}

Corrosion inhibition assumes that the steel electrode corrodes uniformly and that the corrosion current density in the absence of surfactants, $i_{\text {corr }, 0}$, is usually represented by the total number of surface sites available for corrosion, whereas the corrosion current density in the presence of low concentration of inhibitor (usually lower than the cmc or sac), $i_{\text {corr }}$, is 
represented by the number of uncovered surface sites remaining after limited surfactant adsorption [28-30]. Thus, the surface coverage $\theta$ is equal to the fraction of surface sites covered by surfactant adsorption relative to the total surface sites and can be given by the expression below with the assumption that surfactant adsorption does not affect the metal dissolution kinetics of the surface which is not covered by the surfactant [31]:

$$
\theta=\frac{i_{\text {corr }, 0}-i_{\text {corr }}}{i_{\text {corr }, 0}}=1-\frac{i_{\text {corr }}}{i_{\text {corr }, 0}}
$$

The adsorption of surfactants at the surface/interface is usually modeled by a traditional adsorption model. One of the widely accepted models is the Langmuir adsorption isotherm [32], in which the surface coverage is represented by:

$$
\theta=\frac{K_{\mathrm{ad}} C}{1+K_{\mathrm{ad}} C}
$$

or

$$
\frac{1}{\theta}=\frac{1}{K_{\mathrm{ad}} C}+1
$$

$K_{\text {ad }}$ is given by

$$
K_{\mathrm{ad}}=\frac{1}{55.5} \exp \left(-\frac{\Delta G_{\mathrm{ad}}^{0}}{R T}\right)
$$

where $K_{\text {ad }}$ is equilibrium adsorption constant, $C$ is the concentration of total surfactants in the bulk solution, the value 55.5 is the molar concentration of water in solution in moles per liter $(\mathrm{M}), \Delta G_{\text {ad }}^{0}$ is the standard free energy of the adsorption process, $R$ is gas constant, and $T$ is absolute temperature. Note that for pure surfactant, $C$ and $C_{\mathrm{cmc}}$ are total concentration of pure surfactant $i, C_{i}$, in solution and its corresponding $\mathrm{cmc}, C_{\mathrm{cmc}, i}$, respectively; for mixed surfactants, $C$ and $C_{\mathrm{cmc}}$ are total concentration of mixed surfactants, $C_{\text {mix }}$, in solution and their corresponding mixed cmc, $C_{\mathrm{cmc} \text {,mix }}$, respectively.

A plot of $(1 / \theta) v s .1 / C$ (for $C<C_{\mathrm{cmc}}$ ) using Equation (5) based on potentiodynamic scans for Testing System I yields an intercept which gives an equilibrium constant $K_{\text {ad }}$ of a value of $8.13 \times 10^{4} \mathrm{M}^{-1}$, as shown in Figure $4 . C_{\mathrm{cmc}}$ represents the value of $\mathrm{cmc}$. With Equation (6), $\Delta G_{\mathrm{ad}}^{0}$ is calculated and the value is $-39.8 \mathrm{~kJ} \cdot \mathrm{mol}^{-1}$. The negative value demonstrates that the adsorption of surfactant on the steel surface is a spontaneous process and shows a strong interaction between surfactant molecules and steel surface [32]. Generally, if adsorption free energy is more positive than $-20 \mathrm{~kJ} \cdot \mathrm{mol}^{-1}$, the interaction between surfactant and metal is classified as physisorption due to electrostatic interaction. When the adsorption free energy is more negative than $-40 \mathrm{~kJ} \cdot \mathrm{mol}^{-1}$, the adsorption involves charge sharing or transfer between surfactant molecules and metal surface to form coordination bonds, which is also classified as chemisorption [33]. Based on the calculated 
value of adsorption free energy, $-39.8 \mathrm{~kJ} \cdot \mathrm{mol}^{-1}$, the adsorption mechanism of the discussed mixture can be classified as the combination of chemisorption and physisorption. Specifically, the adsorption mechanism of surfactant on steel electrode surface is often interpreted as follows: the unpaired or $\pi$ electrons of the surfactant molecule and the vacant $d$ orbitals of iron share electrons (chemisorption); the charged surfactant and electrode surface interact through electrostatic force (physisorption).

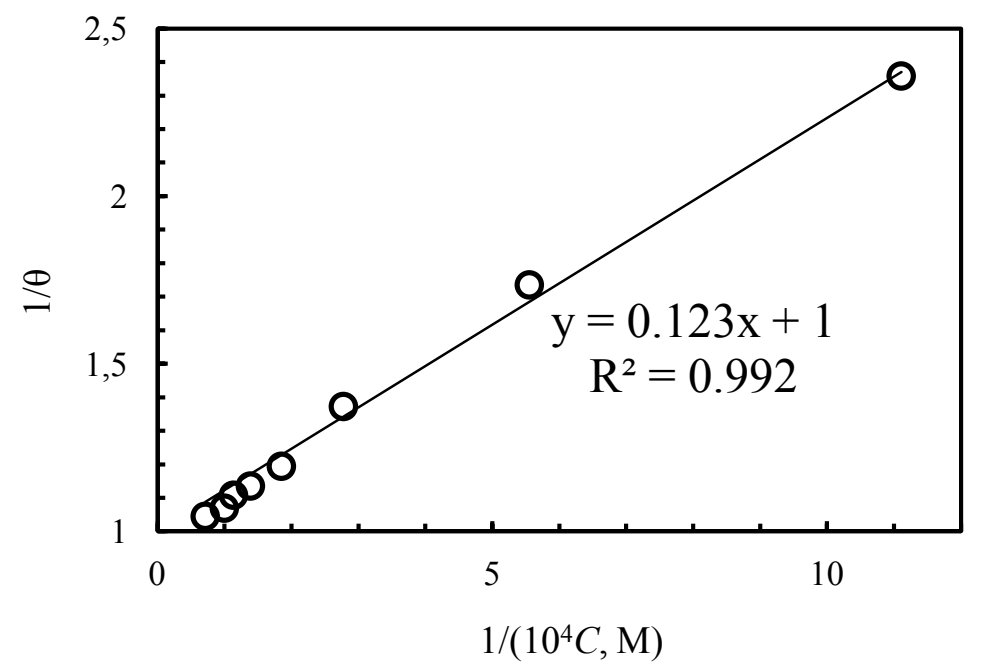

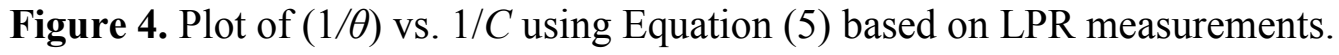

\section{IE prediction model using cmc}

A combination of Equations (3) and (4) and rearrangement lead to a useful equation that correlates the corrosion current density to surfactant concentration [34]:

$$
\frac{1}{i_{\text {corr }}}=\frac{1}{i_{\text {corr }, 0}}+\frac{K_{\mathrm{ad}} C}{i_{\text {corr }, 0}}
$$

There should be a linear relationship between the inverse of corrosion current density $\left(1 / i_{\text {corr }}\right)$ and bulk surfactant concentration $C$ when $C \leq C_{\text {sac }}$. The surfactant adsorption and corrosion inhibition at this level is particularly effective with increasing concentration due to plenty of active surface sites available to be covered by surfactants. Above the sac, an abrupt transition should occur in the slope, because the electrode surface is covered by a complete monolayer. Increasing concentration of the surfactant above the sac should lead to the formation of bilayers/multilayers and micelles (above $\mathrm{cmc}$ ), which slightly contribute to surface coverage and corrosion inhibition. Thus, the sac is an important scaling factor in the determination of the effect of surfactant concentration on adsorption and corrosion inhibition. However, because the cmc is easier to measure than the sac in the present research and due to the availability of a developed prediction model for $\mathrm{cmc}$, the concentration in Equation (7) is normalized by dividing by $C_{\mathrm{cmc}}$, rather than by $C_{\mathrm{sac}}$, and rearranged to give: 


$$
\frac{1}{i_{\text {corr }}}=\frac{1}{i_{\text {corr }, 0}}+\frac{K}{i_{\text {corr }, 0}} \frac{C}{C_{\text {cmc }}}
$$

where $K$ is equal to the adsorption constant $K_{\text {ad }}$ multiplied by $C_{\mathrm{cmc}}$ of surfactant. Further rearrangement leads to a general form which can be used to evaluate corrosion of a variety of surfactants under a variety of test conditions:

$$
\frac{i_{\text {corr }, 0}}{i_{\text {corr }}}=1+K \frac{C}{C_{\text {cmc }}}\left(C \leq C_{\text {sac }}\right)
$$

Note homologous surfactants tend to achieve similar levels of surface coverage at similar ratios of surfactant concentration to surfactant $\mathrm{cmc}$, so the value of $K$ does not vary a lot for homologous surfactants. Note that $C$ could increase above the sac or the cmc, but the fitting is generally not as good as the fitting for $C$ below the sac.

The measured cmc for the mixture, $0.70 / 0.25 / 0.05$ in $0.171 \mathrm{M} \mathrm{NaCl}$ aqueous media at $40^{\circ} \mathrm{C}$, is $144 \mu \mathrm{M}$. A plot of $\frac{i_{\text {corr }, 0}}{i_{\text {corr }}}$ versus $\frac{C}{C_{\text {cmc }}}$ yields a slope of constant $K=13.74$, and an intercept of 1 which is in the absence of inhibitor, as shown in Figure 5. It is also seen in Figure 5 there is one abrupt transition around the concentration of the sac, which indicates that when the inhibitor concentration is below the sac, inhibition efficiency increases rapidly with the increases in concentration; above the sac, the increase in concentration does not contribute much to further inhibition efficiency increase.

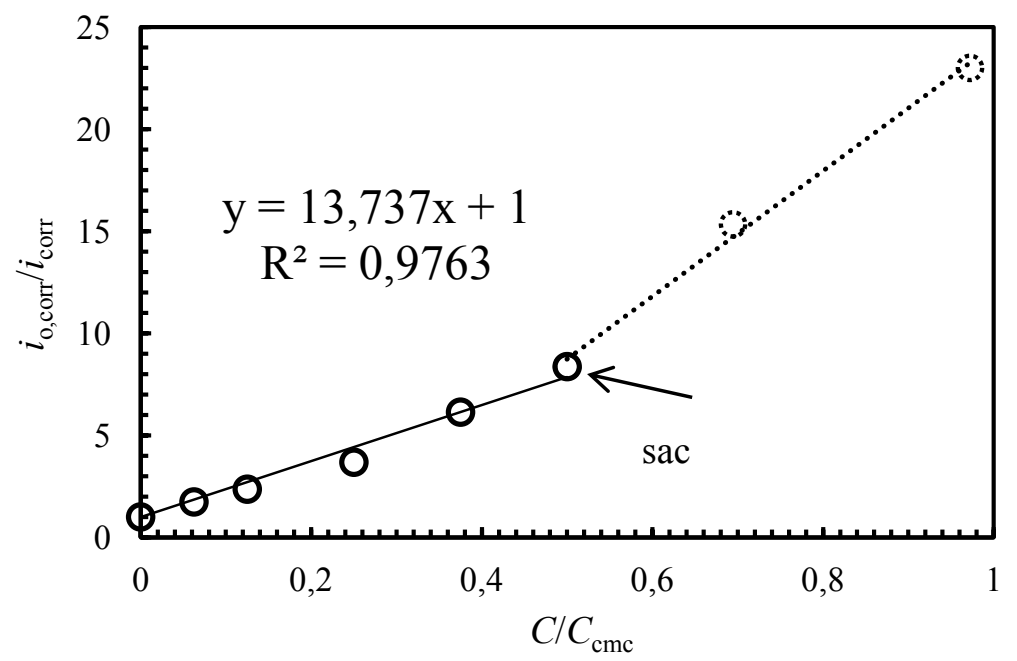

Figure 5. Plot of $\frac{i_{\text {corr }, 0}}{i_{\text {corr }}}$ versus $\left(\frac{C}{C_{\mathrm{cmc}}}\right)$ of X65 steel exposed in $\mathrm{CO}_{2}$-saturated $0.171 \mathrm{M} \mathrm{NaCl}$ aqueous solution containing various concentrations of mixed surfactants $\mathrm{C} 12 \mathrm{Cl}, \mathrm{C} 14 \mathrm{Cl}, \&$ $\mathrm{C} 16 \mathrm{Cl}$ at ratio of $0.70 / 0.25 / 0.05$ at $40^{\circ} \mathrm{C}$.

The cmc prediction model and inhibition efficiency prediction model were validated by performing tests on mixed surfactant $\mathrm{C} 12 \mathrm{Cl} / \mathrm{C} 14 \mathrm{Cl} / \mathrm{C} 16 \mathrm{Cl}=0.33 / 0.33 / 0.33$ with 
$0.599 \mathrm{M} \mathrm{NaCl}$. Figure 6 illustrates a good agreement between predicted inhibition efficiency and experimental inhibition efficiency.

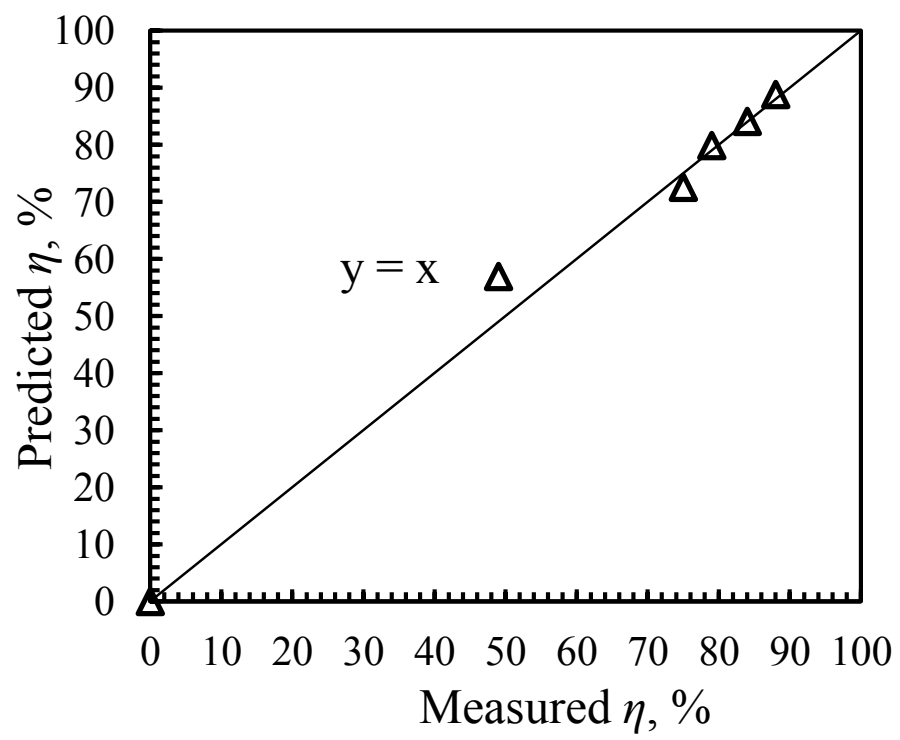

Figure 6. Comparison between experimental inhibition efficiency and predicted inhibition efficiency.

\section{Effect of salt on surfactant aggregation}

Despite extensive progress in theoretical and experimental work has been made in the study of aggregation properties of ionic surfactants the effect of added salt and specific ion (dissociated from surfactants and salt) is still a challenge [35-38]. The ion and salt usually shift cmc, aggregation number of micelle, sphere-to-rod transition, and counterion binding coefficient $[39,40]$. The micelle shape, micelle composition (for mixed surfactants), and micelle distribution are also affected $[39,40]$.

In the present work an improved model based on existing molecular thermodynamic theory $[35,38]$ has been applied to various pure and mixed surfactants. Activities of monomeric surfactant and counterion, which are evaluated from Setchenov equation [41] and Pitzer's method [42] or Davies [43] equation respectively, are incorporated in the model. The specific headgroup-counterion pair is introduced to model counterion specificity. The counterion binding coefficient is initially set as a variable and finds its optimal value by minimizing micellization free energy. The effect of coion is reflected from salt-dependent factors, including Setchenov coefficient $k_{s}$, dielectric decrement of salt $\delta_{\mathrm{s}}$, and the correlation between surface tension and salt concentration of aqueous solution $d \sigma_{0} / d C_{\mathrm{s}}$. The developed model has been applied to pure anionic \& cationic surfactants in aqueous solution containing various salt concentrations for validation.

Assuming the monomeric surfactant $\mathrm{m}_{i}(i=1,2$, or $3 \ldots)$ is completely dissociated in aqueous solution containing counterion $\mathrm{m}_{j}(j=1,2$, or $3 \ldots)$ but in the micelle form the 
surfactant is associated to some extent with counterions, therefore, the surfactant micellization is described by the following process [29, 30, 44, 45]:

$$
n \sum_{i} \alpha_{i} \mathrm{~m}_{i}^{z_{i}}+n \sum_{j} \delta_{j} \mathrm{~m}_{j}^{z_{j}} \leftrightarrow \mathrm{M}_{n \alpha_{i} \delta_{j}}^{n\left(\sum_{i} \alpha_{i} z_{i}+\sum_{j} \delta_{j} z_{j}\right)},
$$

where $\alpha_{i}$ is the composition of surfactant $i$ in the micelle, $\mathrm{M}_{n \alpha_{i} \delta_{j}}$, which has an aggregation number $n$, micelle composition $\alpha_{i}$, and a counterion binding coefficient $\delta_{j}$. For micelles of pure surfactant, $\alpha_{i}=1$; for mixed micelles, $0<\alpha_{i}<1 . z_{i}$ and $z_{j}$ are the valences of ionic surfactant $i$ in dissociated form and counterion $j$. For nonionic surfactant $i, z_{i}=0$ and $\delta_{j}=0$.

By the consideration of activity coefficient, the chemical potential of micelle $\mathrm{M}_{n \alpha_{i} \delta_{j}}$, monomeric surfactant $i$, and counterion $j$ in solution can be written, respectively, as

$$
\begin{gathered}
\mu_{n a_{i} \delta_{j}}=\mu_{n \alpha_{i} \delta_{j}}^{0}+k \ln \left(a_{n \alpha_{i} \delta_{j}}\right)=\mu_{n \alpha_{i} \delta_{j}}^{0}+k T \ln \left(\gamma_{n \alpha_{i} \delta_{j}} X_{n a_{i} \delta_{j}}\right) \\
\mu_{\mathrm{mi}}=\mu_{\mathrm{mi}}^{0}+k T \ln \left(a_{\mathrm{mi}}\right)=\mu_{\mathrm{mi}}^{0}+k T \ln \left(\gamma_{\mathrm{mi}} X_{\mathrm{mi}}\right) \\
\mu_{\mathrm{mj}}=\mu_{m j}^{0}+k T \ln \left(a_{\mathrm{mj}}\right)=\mu_{\mathrm{mj}}^{0}+k T \ln \left(\gamma_{\mathrm{mj}} X_{\mathrm{mj}}\right)
\end{gathered}
$$

where $\mu_{n \alpha_{i} \delta_{j}}^{0}, \mu_{\mathrm{mi}}^{0}$ and $\mu_{\mathrm{mj}}^{0}$ are the standard chemical potentials of micelle, monomeric surfactant, and counterion in solution, respectively. The standard state of water is defined as pure liquid while the standard state of all other species is defined for an infinitely dilute solution. $a_{n \alpha_{i} \delta_{j}}, a_{\mathrm{mi}}$, and $a_{\mathrm{mj}}$ are the corresponding activities. $\gamma_{n a_{i} \delta_{j}}, \gamma_{\mathrm{mi}}$, and $\gamma_{\mathrm{mj}}$ are the corresponding activity coefficients. Micelle is treated as one separated phase from aqueous solution and thus $\gamma_{n a i \delta j}=1 . X_{n a_{i} \delta_{j}}, X_{\mathrm{mi}}$, and $X_{\mathrm{mj}}$ are mole fractions of micelle, monomeric surfactant, and counterion in bulk solution.

The $\mathrm{cmc}$ is assumed to be equal to monomer concentration $X_{\mathrm{m}}$ (here this is the mole fraction) and is calculated by $[29,30]$ :

$$
X_{\mathrm{cmc}}=\exp ^{\left(\frac{1}{k T} \Delta \mu_{\mathrm{m}}^{0}\right)}
$$

The micellization free energy $\Delta \mu_{\mathrm{m}}^{0}$ is estimated from a few contributing terms as described below:

$$
\Delta \mu_{m}^{0}=\Delta \mu_{t r t}^{0}+\Delta \mu_{\text {int }}^{0}+\Delta \mu_{p a c k}^{0}+\Delta \mu_{s t}^{0}+\Delta \mu_{e n t}^{0}+\Delta \mu_{\text {elec }}^{0}+\Delta \mu_{a c t}^{0}
$$

where $\Delta \mu_{t r t}^{0}, \Delta \mu_{i n t}^{0}, \Delta \mu_{p a c k}^{0}, \Delta \mu_{s t}^{0}, \Delta \mu_{\text {ent }}^{0}$, and $\Delta \mu_{\text {elec }}^{0}$ are the free energy contributions from hydrocarbon transfer from water into micelle, formation of micellar core-water interface, hydrocarbon tail packing in the micelle, surfactant headgroup steric interaction, headgroup- 
counterion mixing, and electrostatic interaction, respectively [35, 38]. $\Delta \mu_{a c t}^{0}$ comes from the activity contribution $[29,30]$. Free energy micellization as a function of variables, including on micelle shape $S$, micelle composition $\alpha_{i}(i$ represents surfactant), micellar core minor radius $l_{c}$, and counterion binding coefficient $\delta_{j}(j$ represents ion), at given solution conditions is minimized using home-designed Matlab code. The minimized micellization free energy is then used for the evaluation of cmc, aggregation number, counterion binding coefficient, and sphere-to-rod transition. Details of cmc model derivation and free energy calculation is reported elsewhere $[29,30]$.

The model is applied to pure anionic surfactants, alkali metal dodecyl sulfate XDS, in aqueous solution with various added salts $\mathrm{XCl}\left(\mathrm{X}=\mathrm{Li}^{+}, \mathrm{Na}^{+}, \mathrm{K}^{+}\right.$, and $\left.\mathrm{Cs}^{+}\right)$to examine counterion effect, as shown in Figure 7 which presents the model prediction (various lines) and experimental data (various symbols) of cmc and weight-based aggregation number $n_{w}$. The predicted $\mathrm{cmc}$ agrees well with experiment at low to medium salt concentration $(\sim 1 \mathrm{M})$. Slight deviation is observed above the salt concentration of $1 \mathrm{M}$ as shown in Figure 7(a). The sphere-to-rod transition which is interpreted as the sharp up-turn of $n_{w}$ as a function of salt concentration is clearly seen in Figure 7(b). The predicted $n_{w}$ and experimental $n_{w}$ match reasonably well. The slightly underestimated $n_{\mathrm{w}}$ before the sphereto-rod transition is attributed to the globular structure of surfactant aggregates, rather than regular spherical micelles, and the fact that the model does not incorporate globular micelle. The Hofmeister series, which is $\mathrm{Li}^{+}<\mathrm{Na}^{+}<\mathrm{K}^{+}<\mathrm{Cs}^{+}$for anionic surfactants [39, 40], is correctly reflected by the effect of counterion on the depression of cmc, and on the increment of aggregation number of alkali metal alkyl sulfates.
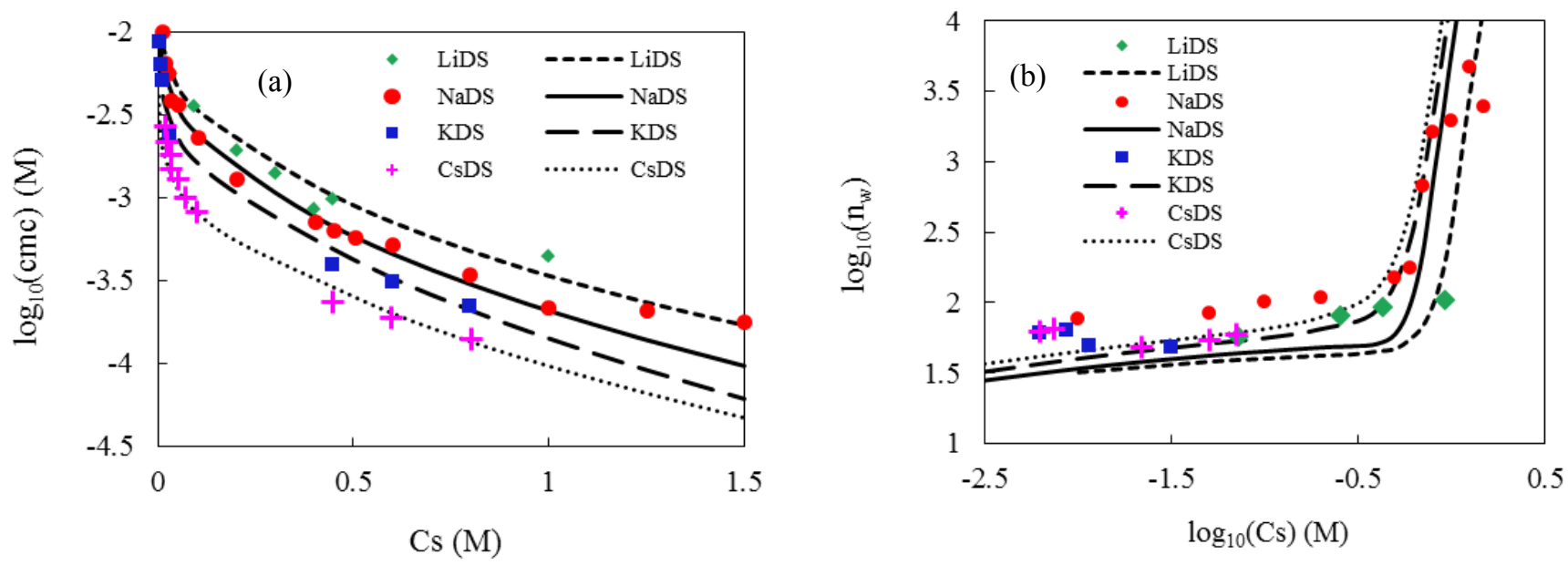

Figure 7. (a) cmc and (b) weight-based aggregation number $n_{\mathrm{w}}$ of alkyl sulfate XDS vs. salt $\mathrm{XCl}$ concentration [30]. $\mathrm{X}=\mathrm{Li}^{+}, \mathrm{Na}^{+}, \mathrm{K}^{+}$, and $\mathrm{Cs}^{+}$. Solid and dashed lines represent model prediction; symbols represent experimental data cited from references [47-52]. Model inputs based on experimental conditions: $25-45^{\circ} \mathrm{C}$, and total solution concentration of surfactant set at $10-100 \mathrm{mM}$ depending on specific surfactant. 
The model is also applied to pure alkyltrimethylammonium surfactant $\mathrm{C}_{n} \mathrm{TABr}$ in solution with added salt $(\mathrm{NaBr}, \mathrm{NaCl}$, or $\mathrm{KCl})$ to evaluate chain length effects, counterion effects, and coion effects on aggregation properties as shown in Figure 8. The cmc (Figure 8(a)) and sphere-to-rod transition threshold (Figure 8(b)) decrease as chain length increases whereas $n_{w}$ (Fig. 8(b)) increases as chain length increases. The predicted cmc for all surfactants in Figure 8 match very well with the experiment except that slight deviation appears for $\mathrm{C}_{12} \mathrm{TABr}$ with added $\mathrm{NaBr}$ above $1 \mathrm{M}$. Excellent agreement is observed between predicted and experimental $n_{w}$. The transition threshold of salt concentration is well predicted as indicated by the change of $n_{\mathrm{w}}$. For $\mathrm{C}_{16} \mathrm{TABr}$ with $\mathrm{KBr}$ for example, the predicted threshold is $0.08 \mathrm{M}$ and the experimental threshold is $0.1 \mathrm{M}$ [46].
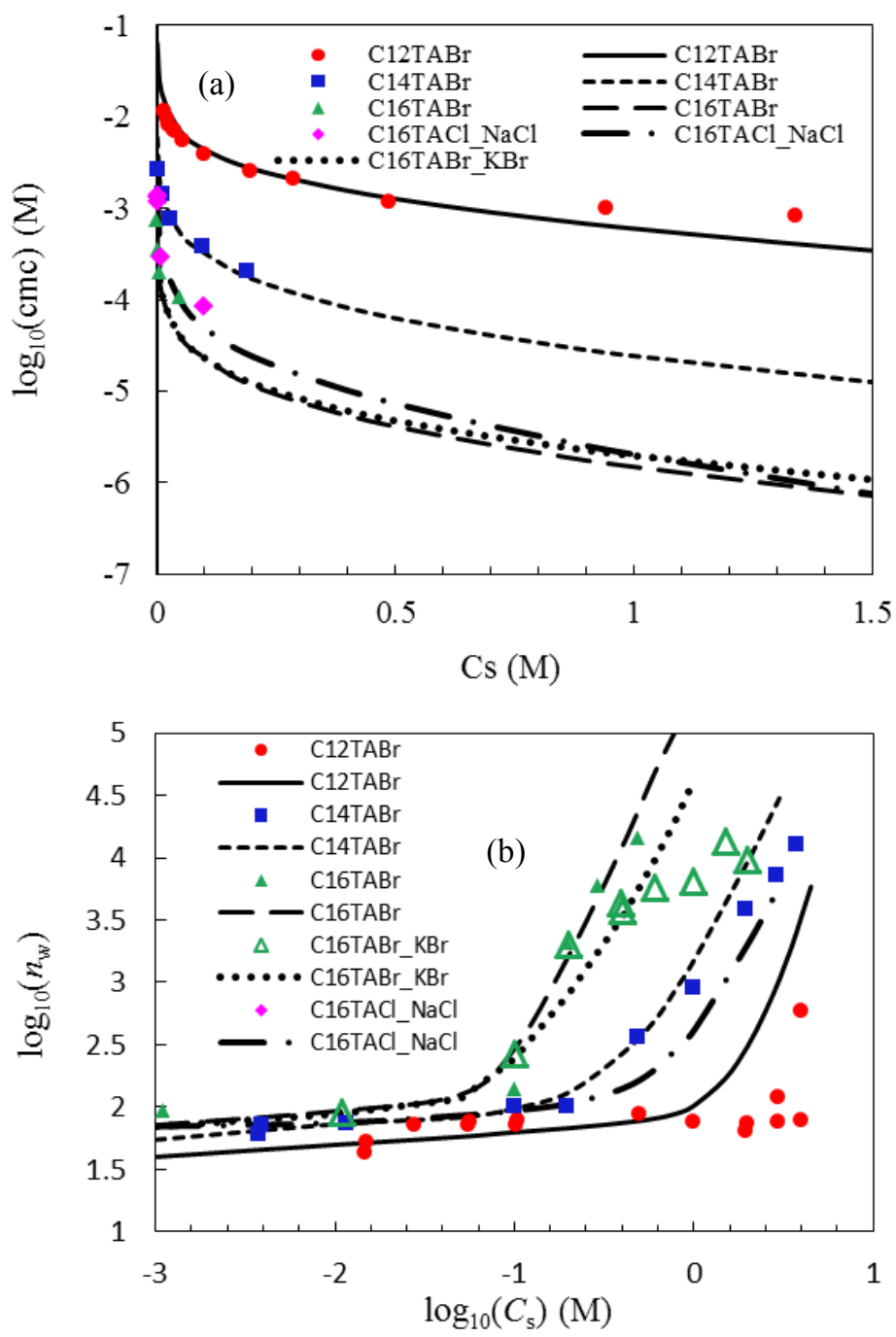

Figure 8. (a) cmc and (b) weight-based aggregation number $n_{\mathrm{w}}$ of alkyltrimethylammonium bromide/chloride $\mathrm{C}_{n} \mathrm{TAX}\left(\mathrm{X}=\mathrm{Br}^{-}, \mathrm{Cl}^{-}\right)$vs. salt concentration [30]. The salt type is specified as it is in the legend; if not specified the salt is $\mathrm{NaBr}$. Solid and dashed lines represent model prediction; symbols represent experimental data cited from references [46, 53-57]. Model inputs based on experimental conditions: $35^{\circ} \mathrm{C}$, and total solution concentration of surfactant set at $10 \mathrm{mM}$ for $\mathrm{C}_{14} \mathrm{TABr}$ and $\mathrm{C}_{16} \mathrm{TABr} / \mathrm{Cl}$ and at $30 \mathrm{mM}$ for $\mathrm{C}_{12} \mathrm{TABr}$. 


\section{Conclusions}

Corrosion inhibition efficiency rapidly increases as the surfactant concentration increases to the sac, indicating the formation of a relatively complete surfactant monolayer around the sac that effectively protects the steel electrode from corrosion. There is excellent agreement among inhibition efficiency measured from potentiodynamic scans and LPR. A new cmc prediction model for various pure and mixed surfactants is developed over a wide concentration range of salt. The improved corrosion inhibition efficiency prediction model which incorporates the cmc prediction is an effective method that can be used for corrosion inhibition prediction of various ternary mixtures of homologous BAC surfactants at various salt concentrations. The corrosion inhibition model presented in this work provides a potential method to evaluate $\mathrm{cmc}$ and corrosion inhibition efficiency of binary-, ternary-, or multiple-component mixtures of surfactants of interest in the presence of salt in solution.

\section{References}

1. P. Bai, H. Zhao, S. Zheng and C. Chen, Corros. Sci., 2015, 93, 109.

2. V. M. Abbasov, L. I. Aliyeva, H. M. A. El-Lateef and I. T. Ismayilov, Int. J. Corros. Scale Inhib., 2015, 4, no. 2, 162. doi: 10.17675/2305-6894-2015-4-2-162-175

3. N. G. Thompson, Y. Mark and D. Daniel, Corros. Rev., 2007, 25, 247.

4. D. A. Lopez, S. N. Simison and S.R. de Sanchez, Electrochim. Acta, 2003, 48, 845.

5. B. R. Linter and G. T. Burstein, Corros. Sci., 1999, 41, 117.

6. Z. Xia, K. C. Chou and Z. S. Smialowska, Corrosion, 1989, 45, 636.

7. K. S. George and S. Nesic, Corrosion, 2007, 63, 178.

8. E. Lyublinski, P Lynch, I. Roytman and T. Yakubovskaya, Int. J. Corros. Scale Inhib., 2015, 4, no. 2, 176. doi: 10.17675/2305-6894-2015-4-2-176-192

9. Yu. I. Kuznetsov, Int. J. Corros. Scale Inhib., 2015, 4, no. 1, 15. doi: $\underline{10.17675 / 2305-}$ 6894-2015-4-1-015-034

10. B. Kronberg, Curr. Opin. Colloid Interface Sci., 1997, 2, 456.

11. R. Tadmouri, C. Zedde, C. Routaboul, J.-C. Micheau and V. Pimienta, J. Phys. Chem. $B, 2008,112,12318$.

12. M. Z. A. Rafiquee, S. Khan, N. Saxena and M. A. Quraishi, J. Appl. Electrochem., 2009, 39, 1409.

13. M. A. Quraishi, A. Singh, V. K. Singh, D. K. Yadav and A. K. Singh, Mater. Chem. Phys., 2010, 122, 114.

14. J. O. Bockris and A. K. N. Reddy, Modern Electrochemistry, 2nd ed., Kluwer Academic/Plenum Publishers, New York, 2000.

15. A. Kokalj, S. Peljhan, M. Finsgar and I. Milosev, J. Am. Chem. Soc., 2010, 132, 16657.

16. R. M. Hill, Mixed Surfactant systems, Marcel Dekker, New York, 1993.

17. Y. Zhu and M. L. Free, ECS Transactions, 2015, 66, 53. doi:10.1149/06617.0053ecst

18. Sonu, A. K. Tiwari and S. K. Saha, Ind. Eng. Chem. Res., 2013, 52, 5895.

19. A. Graciaa, J. Anderez, C. Bracho, J. Lachaise, J.-L. Salager, L. Tolosa and F. Ysambertt, Adv. Coll. Interf. Sci., 2006, 123-126, 63. 
20. C. G. Tohren and L. Chen, Coll. Surf. A: Physicochem. Eng. Aspects, 2008, 326, 73.

21. M. Balcan and D. Anghel, Coll. Poly. Sci., 2005, 283, 982.

22. M. A. Cowell, T. C. G. Kibbey, J. B. Zimmerman and K. F. Hayes, Environ. Sci. Technol., 2000, 34, 1583.

23. S. Ikea, S. Hayashi and T. Imae, J. Phys. Chem., 1981, 85, 106.

24. L. Abezgauz, K. Kuperkar, P. A. Hassan, O. Ramon, P. Bahadur and D. Danino, J. Coll. Interf. Sci., 2010, 342, 83.

25. C. Oelschlaeger, P. Suwita and N. Willenbacher, Langmuir, 2010, 26, 7045.

26. M. Knag, K. Bilkova, E. Gulbrandsen, P. Carlsen and J. Sjoblom, Corros. Sci., 2006, 48, 2592.

27. O. L. Riggs Jr., Corrosion Inhibitors, 2nd ed., C. C. Nathan, Houston, TX, 1973.

28. Y.Zhu, M. L. Free and G. Yi, Corros. Sci., 2015, 98, 417. doi: 10.1016/ j.corsci.2015.05.050

29. Y. Zhu, M. L. Free and G. Yi, J. Electrochem. Soc., 2015, 162, C582. doi: $\underline{10.1149 /}$ 2.09415010jes

30. Y.Zhu, M. L. Free, Ind. Eng. Chem. Res., 2015， 54, 9052. doi: 10.1021/ acs.iecr.5b02103

31. Yu. I. Kuznetsov, N. N. Andreev and S. S. Vesely, Int. J. Corros. Scale Inhib., 2015, 4, no. $2,108$.

32. M. Christov and A. Popova, Corros. Sci., 2004, 46, 1613.

33. P. C. Okafor and Y. Zheng, Corros. Sci., 2009, 51, 850.

34. M. L. Free, Corros. Sci., 2004, 46, 3101.

35. R. Nagarajan and E. Ruchenstein, Langmuir, 1991, 7, 2934.

36. V. Srinivasan and D. Blankschtein, Langmuir, 2003, 19, 9946.

37. M. J. Rosen, Surfactants and Interfacial Phenomena, 3rd Ed., Wiley, New York, 2004.

38. L. Moreira and A. Firoozabadi, Langmuir, 2010, 26, 15177.

39. C. Oelschlaeger, P. Suwita and N. Willenbacher, Langmuir, 2010, 26, 7045.

40. N. Vlachy, B. Jagoda-Cwiklik, R. Vácha, D. Touraud, P. Jungwirth and W. Kunz, $A d v$. Coll. Interf. Sci., 2009, 146, 42.

41. R. P. Schwarzenbach, P. M. Gschwend and D. M. Imboden, Environmental Organic Chemistry, 2nd Ed., John Wiley and Sons, New York, 2001.

42. J. F. Zemaitis, D. M. Clark, M. Rafal and N.C. Scrivner, Handbook of Aqueous Electrolyte Thermodynamics, AlChE, New York, 1986.

43. J. N. Butler, Ionic Equilibrium: Solubility and pH Calculations, Wiley, New York, 1998.

44. J. N. Phillips, Trans. Faraday Soc., 1955, 51, 561.

45. M. Bourrel and R. S. Schechter, Microemulsions and Related Systems: Formation, Solvency, and Physical Properties, Eds., Marcel Dekker, Inc., New York, NY, 1988.

46. Z. Weican, L. Ganzuo, M. Jianhai, S. Qiang, Z. Liqiang, L. Haojun and W. Chi, Chin. Sci. Bull., 2000, 45, 1854.

47. M. F. Emerson and A. Holtzer, J. Phys. Chem., 1967, 71, 1898. 
48. S. Hayashi and S. Ikeda, J. Phys. Chem., 1980, 84, 744.

49. P. J. Missel, N. A. Mazer, G. B. Benedek and M. C. Carey, J. Phys. Chem., 1983, 87, 1264.

50. P. J. Missel, N. A. Mazer, M. C. Carey and G. B. Benedek, J. Phys. Chem., 1989, 93, 8354.

51. D. Nguyen and G. L. Bertrand, J. Phys. Chem., 1992, 96, 1994.

52. A. Y. Vlasov, K. R. Savchuk, A. A. Starikova and N. A. Smirnova, Zhidk. Krist. Ikh Prakt. Ispol'z., 2011, 4, 90 (in Russian).

53. S. Ozeki and S. Ikeda, Coll. Polym. Sci., 1984, 262, 409.

54. T. Imae, R. Kamiya and S. Ikeda, J. Coll. Interf. Sci., 1985, 108, 215.

55. T. Imae and S. Ikeda, J. Phys. Chem., 1986, 90, 5216.

56. H. Nomura, S. Koda, T. Matsuoka, T. Hiyama, R. Shibata and S. Kato, J. Coll. Interf. Sci., 2000, 230, 22.

57. A. Khatory, F. Lequeux, F. Kern and S. J. Candau, Langmuir, 1993, 9, 1456. 